\title{
Analisis karakteristik aerodinamika telescopic wing dengan konfigurasi sayap flying wing dan glider menggunakan metode pendekatan simulasi CFD
}

\author{
Azhim Asyratul Azmi ${ }^{1 *}$, Satriawan Dini Hariyanto ${ }^{2}$, Arif Hidayat ${ }^{3}$ \\ ${ }^{1}$ Prodi Teknik Mesin, Fakultas Teknik, Universitas Muhammadiyah Yogyakarta \\ JI. Brawijaya, Kasihan, Bantul, Daerah Istimewa Yogyakarta, Indonesia \\ 2Jurusan Teknik Mesin, Fakultas Teknologi Industri, Institut Teknologi AKPRIND \\ Jl. Kalisahak No.28 Kompleks Balapan, Daerah Istimewa Yogyakarta, Indonesia \\ ${ }^{3}$ Program Studi D3 Teknik Mesin, Politeknik LPP \\ JI. LPP No.1 Daerah Istimewa Yogyakarta, Indonesia \\ *Corresponding author. azhim.asyratul.azmi@gmail.com
}

\begin{abstract}
A telescopic wing is a shape-changing method of the aircraft wing known as the morphing wing system. Wingspan extends capability on telescopic wing increasing the aspect ratio to get a high lift force. The telescopic wing on a flying wing configuration as an external wing and glider wing as an internal wing can be used to increase the coefficient lift $\left(C_{L}\right)$ when carrying out special missions. The aerodynamic characteristics using the Computational Fluid Dynamic (CFD) simulation approach is presented. For the $40 \%$ internal wingspan, the highest $C_{L}$ increment was $12.9 \%$ at a $10^{\circ}$ angle of attack. For the $50 \%$ internal wingspan, the highest $C_{L}$ increment was $14.9 \%$ at a $10^{\circ}$ angle of attack. on the $40 \%$ internal wing, the highest coefficient drag $\left(C_{D}\right)$ increment was $4.7 \%$, and the largest $C_{D}$ increment on $50 \%$ internal was $9.5 \%$ at the angle of attack of $20^{\circ}$. The pressure distribution along the internal wingspan was uneven from an angle of attack of $15^{\circ}$ due to the wing tip vortices of the external wing. Streamline pattern shown a bubble separation from the leading edge at an internal wing root by external wing tip vortices.
\end{abstract}

Keywords: Morphing wing, telescopic wing, flying wing, glider

\begin{abstract}
Abstrak
Telescopic wing adalah salah satu metode dari perubahan bentuk sayap pesawat atau yang dikenal dengan morphing wing system. Pada telescopic wing, wingspan memanjang menjadi ukuran tertentu untuk meningkatkan gaya angkat. Teleskopic wing dengan konfigurasi flying wing sebagai sayap eksternal serta sayap glider sebagai sayap internal dapat digunakan untuk meningkatkan nilai coefficient lift $\left(\mathrm{C}_{\mathrm{L}}\right)$ ketika menjalankan misi tertentu. Karakteristik aerodinamika telah dikaji menggunakan pendekatan simulasi Computational Fluid Dynamic (CFD). Pada penelitian ini diperoleh bahwa peningkatan nilai $\mathrm{C}_{\mathrm{L}}$ tertinggi untuk sayap internal $40 \%$ adalah sebesar $12,9 \%$ pada sudut serang $10^{\circ}$. Sedangkan pada sayap internal $50 \%$, peningkatan nilai $C_{L}$ tertinggi yaitu $14,9 \%$ pada sudut serang $10^{\circ}$. Peningkatan nilai coefficient drag $\left(\mathrm{C}_{\mathrm{D}}\right)$ terjadi siring kenaikan sudut serang. Kenaikan nilai $\mathrm{C}_{\mathrm{D}}$ terbesar pada sayap internal $40 \%$ adalah sebesar $4,7 \%$ sedangkan pada sayap internal $50 \%$ kenaikan $C_{D}$ terbesar yaitu $9,5 \%$ pada sudut serang $20^{\circ}$. Distribusi tekanan sepanjang wingspan pada sayap internal tidak merata mulai dari sudut serang $15^{\circ}$ akibat dari wing tip vortices sayap eksternal. Wing tip voritces pada menyebabkan bubble separation pada leading edge yang terlihat dari pola streamline.
\end{abstract}

Kata kunci: Morphing wing, telescopic wing, flying wing, glider

\section{Pendahuluan}

Telescopic wing adalah salah satu metode dari perubahan bentuk sayap pesawat atau yang dikenal dengan morphing wing system [1]. Beragam jenis sistem morphing wing telah banyak dikembangkan, 
diantaranya adalah variation chamber wing [2], variable wing sweep [3], dan variable wing chord [4]. Telescopic wing merupakan desain konseptual pesawat yang mampu mengakomodasi model penerbangan yang berbeda sehingga dapat digunakan untuk menjalankan misi penerbangan yang berubah-ubah. Telescopic wing dirancang untuk menjaga pesawat dapat terbang dengan efisien pada kecepatan yang berbeda-beda [5].

Pada telescopic wing, wing span memanjang menjadi ukuran tertentu sehingga meningkatkan aspek rasio sayap untuk mendapatkan nilai gaya angkat yang lebih baik [6]. Salah satu misi yang membutuhkan jenis pesawat ini adalah pemantauan udara pada korban kecelakaan pendakian gunung. Misi seperti ini menuntut pesawat harus terbang dengan kecepatan tinggi menuju titik asumsi kecelakaan, kemudian terbang dengan kecepatan rendah untuk melakukan pemantauan agar lebih efektif.

Model penerbangan dengan kecepatan tinggi pada skala pesawat model umumnya menggunakan jenis flying wing. Wing span yang relatif pendek serta desain pesawat yang tidak memiliki vertical stabilizer dan elevator, mampu meminimalisir coefficient drag $\left(C_{D}\right)$ sehingga lebih efektif untuk terbang cepat dan bermanuver. Flying wing dengan panjang wing span 1,06 $\mathrm{m}$ mampu terbang hingga kecepatan maksimum 22,6 $\mathrm{m} / \mathrm{s}$ menggunakan motor brushless 16/15/6 dan propeller $7 \times 4$ [7].

Untuk model penerbangan dengan kecepatan terbang rendah, pesawat model jenis glider sangat relevan untuk diaplikasikan. Pesawat glider memiliki coefficient lift $\left(C_{L}\right)$ yang tinggi hingga mampu terbang dengan kecepatan rendah dan efiesiensi penggunaan motor penggerak lebih baik [8].

Perbedaan mendasar pada pesawat model flying wing dan glider adalah jenis airfoil yang digunakan. Flying wing menggunakan airfoil jenis reflexed, yaitu airfoil semi-simetris untuk pesawat yang membutuhkan tingkat manuver yang tinggi.
Sementara itu, pesawat glider menggunakan tipe airfoil under chambered yang merupakan jenis airfoil dengan $C_{L}$ yang tinggi [9].

Misi pemantauan kecelakaan pendakian gunung, dapat menggunakan perpaduan pesawat jenis flying wing dan glider yang menerapkan metode telescopic wing. Sayap flying wing dibagi menjadi dua yaitu sayap eksternal dan internal. Sayap eksternal merupakan sayap flying wing dengan airfoil jenis reflexed dan sayap pesawat glider menjadi sayap internal yang diposisikan di dalamnya. Ketika telah mencapai titik asumsi kecelakaan pendakian gunung, sayap internal dengan airfoil glider dapat dikeluarkan untuk meningkatkan nilai $C_{L}$.

Karakteristik aerodinamika dari telescopic wing perpaduan flying wings dan glider dapat diketahui menggunakan metode pendekatan Simulasi Computational Fluid Dynamic (CFD). Pada penelitian ini akan dilakukan simulasi untuk mengetahui pengaruh telescopic wing pada konfigurasi sayap flying wing dan glider yang belum pernah dilakukan sebelumnya. Karakteristik aerodinamika pada penilitian ini meliputi nilai $C_{L}$ dan $C_{D}$ serta distribusi tekanan pada sayap. Untuk meningkatkan ketilitian, pendekatan simulasi CFD dilakukan menggunakan software ANSYS Fluent yang merupakan software metode pendekatan numerik kontrol volume.

\section{Metode Penelitian}

Pada penelitian ini simulasi dibagi menjadi 3 tahapan, yaitu pre-processing, processing, dan post-processing. Pada tahap preprocessing akan dilakukan pembentukan model 3D, pembentukan computational domain, pembentukan mesh serta pengaturan boundary condition. Tahap processing meliputi perhitungan terhadap parameter yang telah diberikan sebelumnya. Selanjutnya akan dilakukan tahap postprocessing untuk pengambilan data $C_{L}$ dan $C_{D}$ serta kontur aliran.

Pesawat yang dijadikan objek pada penelitian ini merupakan flying wings 
dengan wingspan $1800 \mathrm{~mm}$. Ukuran wingspan mengacu pada flying wing yang umum digunakan untuk misi pemantauan dan observasi yaitu Skywalker X7. Tahap pembentukan model 3D pesawat dilakukan terlebih dahulu sebelum pembentukan mesh seperti yang ditunjukkan pada Gambar 1 .

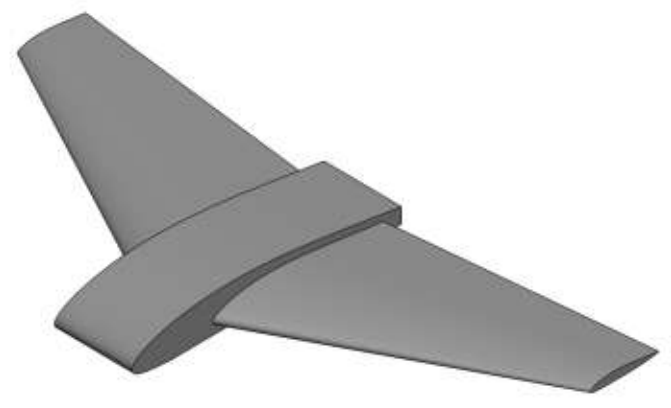

Gambar 1. Model 3D Flying Wings

Airfoil yang digunakan pada sayap flying wing pada penilitian ini adalah NACA M6 yang merupakan airfoil jenis reflexed. Chord pada root sebesar $550 \mathrm{~mm}$ dengan sweep angle sayap $27^{\circ}$ dan chord pada wing tip sebesar $220 \mathrm{~mm}$. Pemilihan NACA M6 didasari oleh profil airfoil yang memiliki luas area yang besar pada thickness $100 \%$, sehingga memiliki ruang lebih untuk peletakkan sayap internal (Gambar 2).

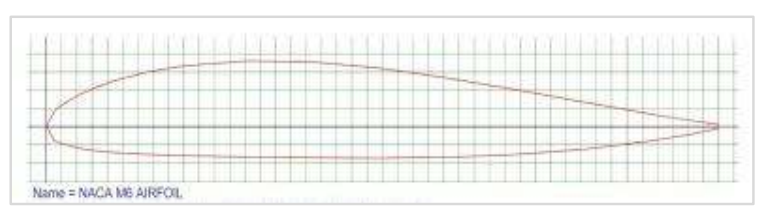

Gambar 2. Profil Airfoil NACA M6

Airfoil pada sayap internal yang adalah Eppler E387 yang banyak digunakan pada pesawat Glider. Eppler E387 memiliki kemampuan untuk memproduksi gaya angkat yang besar pada sudut serang yang rendah [10]. Ukuran keseluruhan airfoil sayap internal harus lebih kecil agar dapat diletakkan pada sayap eksternal dengan menjaga tingkat ketebalan airfoil tetap pada 100\% (Gambar 3).

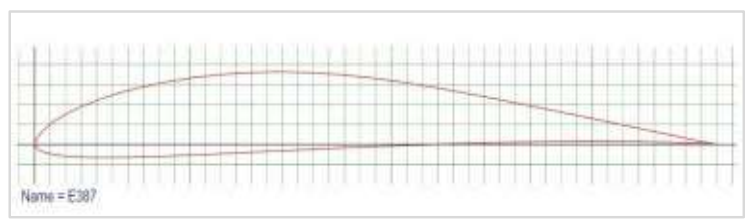

Gambar 3. Profil Airfoil Eppler E387
Persentase wingspan sayap internal terhadap saya eksternal sebesar $40 \%$ dan $50 \%$. Persentase wingspan tersebut mempertimbangkan panjang maksimal sayap agar tidak melebihi posisi servo penggerak elevon. Pada penelitian ini panjang chord sayap internal adalah $190 \mathrm{~mm}$ yang diposisikan $6 \mathrm{~mm}$ di belakang leading edge sayap eksternal.

Luas alas sayap meningkat ketika sayap internal dibentangkan. Luas alas sayap pesawat tanpa sayap internal adalah sebesar $0,83351 \mathrm{~m}^{2}$. Ketika sayap internal dibentangkan $40 \%$, luas alas sayap menjadi $0,95513 \mathrm{~m}^{2}$ dan meningkat hingga 1,12235 $\mathrm{m}^{2}$ ketika menggunakan sayap internal $50 \%$ (Gambar 4).

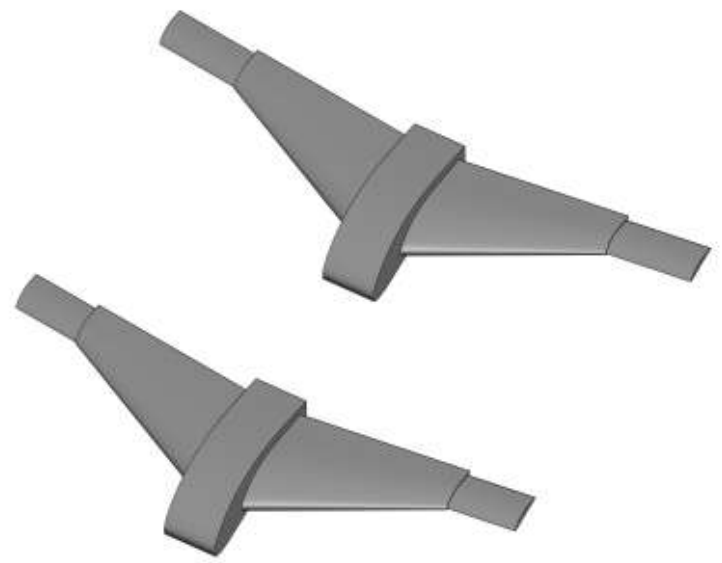

Gambar 4. Flying wings dengan sayap internal Glider $40 \%$ dan $50 \%$

Setelah objek penelitian dibentuk, langkah selanjutnya adalah pembuatan computational domain. Computational domain pada penelitian ini terbagi menjadi domain atmosfir dan domain pesawat. Domain atmosfir memiliki panjang $5 \mathrm{~L}$ dan lebar 2L dimana $\mathrm{L}$ adalah panjang fuselage pesawat. Jarak pesawat terhadap inlet adalah sebesar 1L. Simulasi pada penelitian ini hanya menggunakan setengah dari keseluruhan lebar computational domain dengan mempertimbangkan computational time dan jumlah mesh yang terbentuk. Selanjutnya akan dilakukan mirroring pada post processing (Gambar 5). 


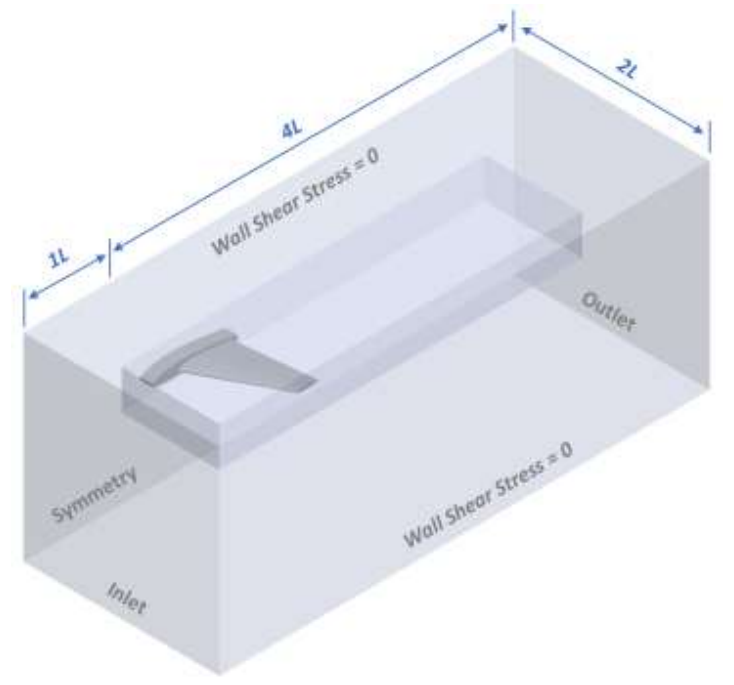

Gambar 5. Computational domain simulasi

Pembentukan mesh dilakukan menggunakan Ansys Meshing. Mesh yang digunakan pada penelitian ini adalah kombinasi tetrahedral mesh dan wedge mesh dengan body of influence sizing sebagai metode refinement. Pengaruh dari body influence sizing terlihat dari jumlah mesh yang terbetuk lebih banyak di sekitar domain pesawat dan daerah di belakang pesawat yang merupakan jalur aliran wake pesawat (Gambar 6).

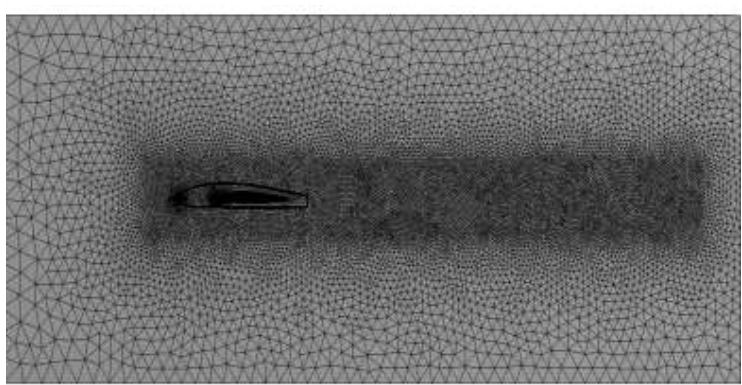

Gambar 6. Hasil Pembentukkan Mesh

Penggunaan body of influence bertujuan untuk meningkat akurasi di perhitungan di sekitar pesawat. Usaha untuk meningkatkan akurasi di perhitungan juga dilakukan dengan penggunaan inflation pada elemen mesh yang berhubungan langsung dengan domain pesawat, seperti yang ditunjukkan Gambar 7. Penggunaan inflation membentuk mesh jenis wedge mesh yang menyelimuti domain pesawat.

Jumlah mesh yang terbentuk adalah sebanyak 6.066.429 elemen, dengan jumlah elemen terbanyak berada di tingkat skewness 0,13. Ukuran mesh yang dihasilkan bervariasi dengan ukuran terkecil adalah $0,000114 \mathrm{~m}$.

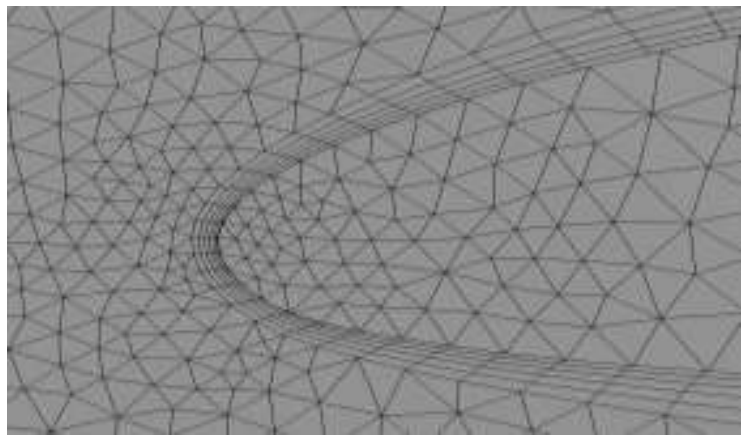

Gambar 7. Inflation pada elemen yang berhubungan langsung dengan domain pesawat

Penentuan jenis dan nilai boundary condition dilakukan setelah mesh berhasil terbentuk. Pada bagian inlet digunakan boundary condition jenis jenis velocity inlet sebesar $15 \mathrm{~m} / \mathrm{s}$ yang merupakan asumsi kecepatan terbang dari pesawat. Bagian outlet mengunakan pressure outlet sebesar 1 atm atau $101325 \mathrm{~Pa}$. Pada bagian sisi atas, bawah, dan samping domain atmosfir digunakan boundary condition jenis wall dengan shear stress wall sebesar 0. Pada domain pesawat jenis boundary condition yang digunakan adalah wall dengan kondisi no slip wall.

Simulasi pada penelitian ini dijalankan dalam kondisi RANS steady state. Model turbulen yang digunakan adalah Standar $K$-Epsilon dengan penambahan parameter scalable wall function. Pada solution method, pressurevelocity coupling menggunakan skema Coupled. Luas area domain pada reference value diberikan nilai sesuai dengan luas area sayap.

Hasil yang akan dicapai dari penelitian ini adalah karakteristik aerodinamika dari penerapan telescoping wing yang berupa informasi nilai $\mathrm{C}_{\mathrm{L}}$ dan $\mathrm{C}_{\mathrm{D}}$. Pengamatan dilakukan pada konfigurasi variasi pesawat tanpa sayap internal, sayap internal $40 \%$ dan sayap internal $50 \%$. Nilai $C_{L}$ dan $C_{D}$ pada setiap variasi juga akan dilakukan pengamatan untuk sudut serang $0^{\circ}, 10^{\circ}, 15^{\circ}$, dan $20^{\circ}$. Pengambilan data dilakukan ketika tidak terjadi lagi fluktuasi grafik hasil nilai $C_{L}$ dan $C_{D}$ untuk setiap iterasi. Proses perhitungan akan dinyatakan 
selesai ketika kriteria konvergen telah tercapai, yaitu sebesar 0,001 . Selain nilai $C_{L}$ dan $C_{D}$, akan dilakukan juga observasi terhadap kontur kecepatan dan tekanan.

\section{Hasil dan Pembahasan}

Simulasi telah dilakukan menggunakan bantuan software Ansys Fluent. Konvergensi tercapai untuk setiap variasi sudut serang.

Hasil studi numerik menunjukkan bahwa penambahan sayap internal pesawat mampu meningkatkan nilai $C_{L}$. Nilai $C_{L}$ terbesar pada pasawat tanpa sayap internal adalah 1,0 yang diperoleh pada sudut serang $15^{\circ}$ seperti yang ditunjukkan pada Gambar 8 .

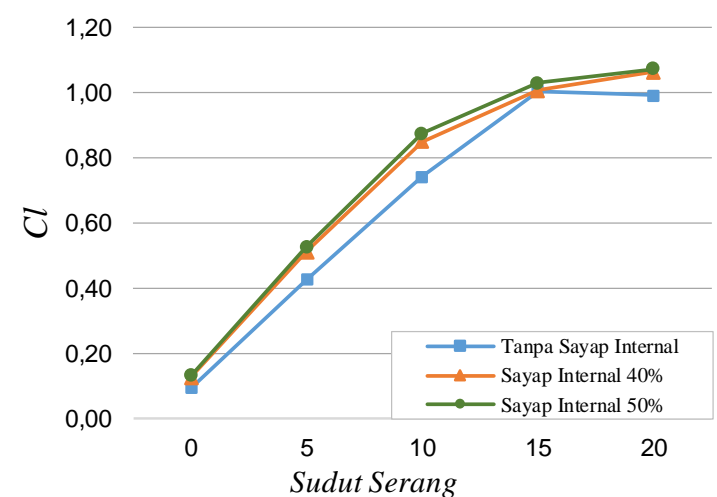

Gambar 8. Grafik Korelasi Sudut Serang terhadap $\mathrm{C}_{\mathrm{L}}$

Peningkatan nilai $\mathrm{C}_{\mathrm{L}}$ terbesar ketika menggunakan sayap internal diperoleh pada sudut serang $10^{\circ}$. Pada sudut serang $10^{\circ}$, flying wing tanpa sayap internal memiliki nilai $C_{L}$ sebesar 0,74 . Nilai $C_{L}$ kemudian meningkat menjadi 0,85 atau sebesar $12,9 \%$ menggunakan sayap internal $40 \%$. Selanjutnya $\mathrm{C}_{\mathrm{L}}$ terus meningkat menjadi 0,87 atau sebesar $14,9 \%$ ketika menggunakan sayap internal $50 \%$.

Penggunaan sayap internal baik $40 \%$ maupun 50\% meningkatkan stall point pada pesawat. Hal ini seperti yang ditunjukkan Gambar 8, dimana pada sudut serang $20^{\circ}$ pesawat tanpa sayap internal mulai kehilangan gaya angkat. Sementara itu, dengan menggunakan sayap internal gaya angkat pesawat masih menunjukkan tren meningkat yang ditandai dengan grafik $C_{L}$ yang masih meningkat.
Nilai $\mathrm{C}_{\mathrm{L}}$ tertinggi dengan konfigurasi sayap internal $40 \%$ dan $50 \%$ terjadi pada sudut serang $20^{\circ}$ dan memiliki nilai yang hampir sama. Pada bentangan sayap internal $40 \%, \mathrm{C}_{\mathrm{L}}$ yang diperoleh adalah sebesar 1,06 sedangkan pada bentangan sayap internal $50 \%$ diperoleh nilai $C_{L}$ sebesar 1,07 . Hal ini dikarenakan perbedaan panjang yang tidak terlalu signifikan antara sayap internal $40 \%$ dan $50 \%$.

Hasil simulasi menunjukkan terjadi kenaikan $C_{D}$ ketika pesawat menggunakan sayap internal. Kenaikan nilai $C_{D}$ tidak terlalu signifikan seperti yang ditunjukkan Gambar 9.

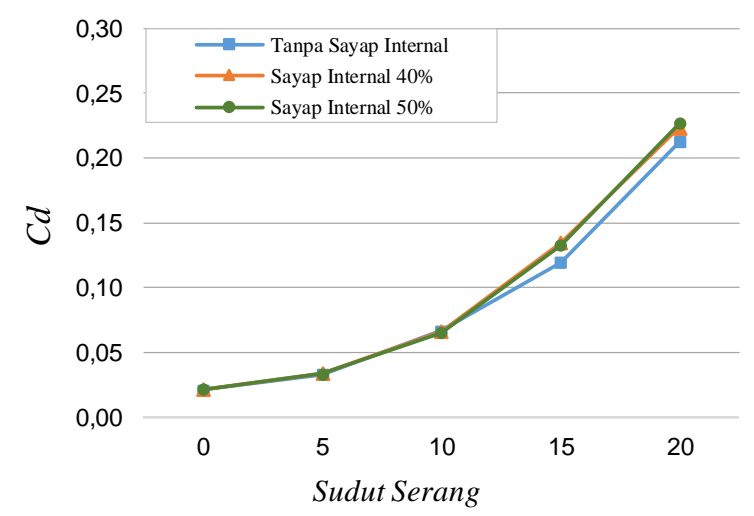

Gambar 9. Grafik Korelasi Sudut Serang terhadap $\mathrm{C}_{\mathrm{D}}$

Pada pesawat tanpa sayap internal, nilai $C_{D}$ tertinggi yang diperoleh adalah sebesar 0,21. Ketika menggunakan sayap internal $40 \%$ nilai $\mathrm{C}_{\mathrm{D}}$ tertinggi adalah sebesar 0,22 atau terjadi kenaikan sebesar $4,7 \%$. Nilai $C_{D}$ tertinggi pada sayap internal $50 \%$ adalah sebesar 0,23 atau terjadi kenaikan sebesar $9,5 \%$ dibandingkan pesawat tanpa sayap internal. Nilai $C_{D}$ tertinggi ketika menggunakan sayap internal diperoleh pada sudut serang $20^{\circ}$.

Tahap post processing pada penelitian ini menggunakan software CFD Post untuk mendapatkan kontur distribusi tekanan pada bagian sayap pesawat. Kontur tekanan pada pesawat tanpa sayap internal untuk setiap variasi sudut serang ditunjukkan pada Gambar 10. 


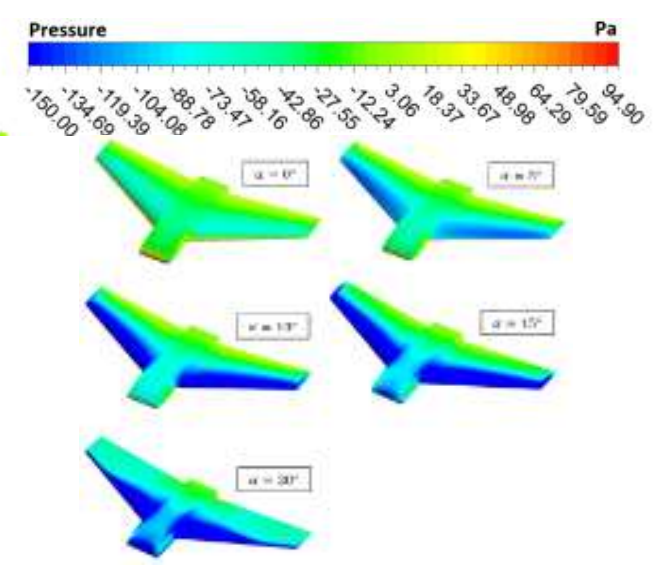

Gambar 10. Kontur Distribusi Tekanan pada Pesawat Tanpa Sayap Internal

Pada Gambar 10 dapat diketahui bahwa distribusi tekanan pada sayap pesawat terfokus pada bagian daerah sekitar leading edge. Pada sudut serang $0^{\circ}$ terlihat distribusi tekanan negatif belum terbentuk dengan sempurna yang ditandai dengan kontur dari permukaan sayap bagian atas didominasi warna hijau. Kondisi seperti ini menandakan gaya angkat pesawat yang relatif rendah.

Tekanan negatif mulai terbentuk optimal pada sudut serang $5^{\circ}$ dimana permukaan atas sayap mulai mulai tampak berwarna biru yang kemudian terus terdistribusi dengan baik hingga sudut serang $15^{\circ}$. Pada sudut serang $20^{\circ}$ tekanan negatif pada permukaan sayap berkurang hampir setengah dari wingspan akibat dari separasi aliran udara.

Pengamatan yang sama dilakukan pada pesawat dengan sayap internal $40 \%$. Distribusi tekanan yang dihasilkan memiliki karakteristik yang serupa dengan pesawat tanpa sayap internal seperti yang ditunjukkan pada Gambar 11.

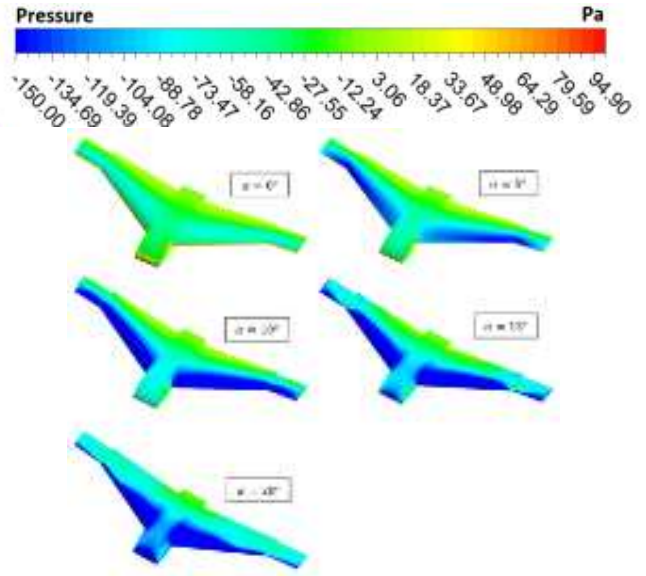

Gambar 11. Kontur Distribusi Tekanan pada Pesawat dengan Sayap Internal 40\%

Pesawat dengan sayap internal $40 \%$ terlihat memiliki distribusi tekanan negatif yang baik pada sudut serang $10^{\circ}$. Tekanan negatif mencapai -150 Pa di seluruh daerah leading edge sayap eksternal maupun sayap internal, namun pada sudut serang $15^{\circ}$, tekanan negatif pada sayap internal mulai berkurang.

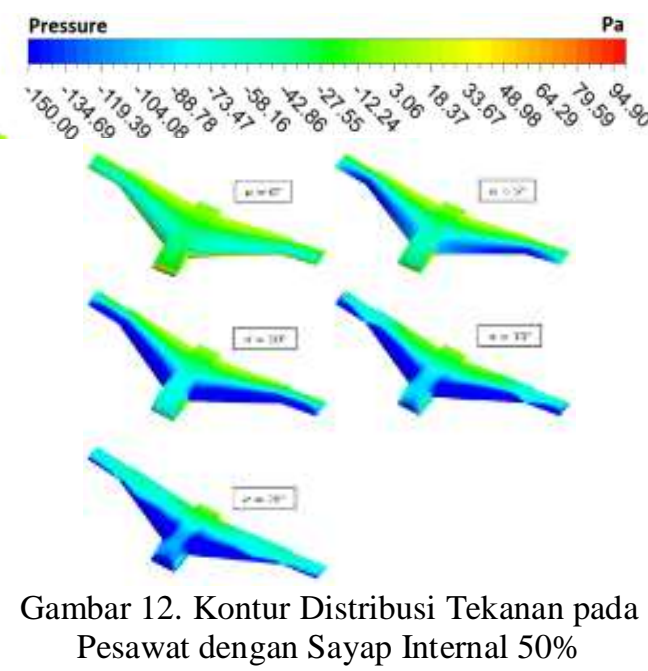

Hal ini terjadi karena ukuran chord dan ketebalan kedua jenis sayap tersebut berbeda, sehingga terjadi wing tip vortices pada sayap eksternal. Wing tip vortices yang terbentuk pada sayap eksternal mengakibatkan tekanan tidak terdistribusi dengan baik pada sayap internal, hal ini ditunjukkan oleh visualisasi pola streamline aliran pada Gambar 13. 


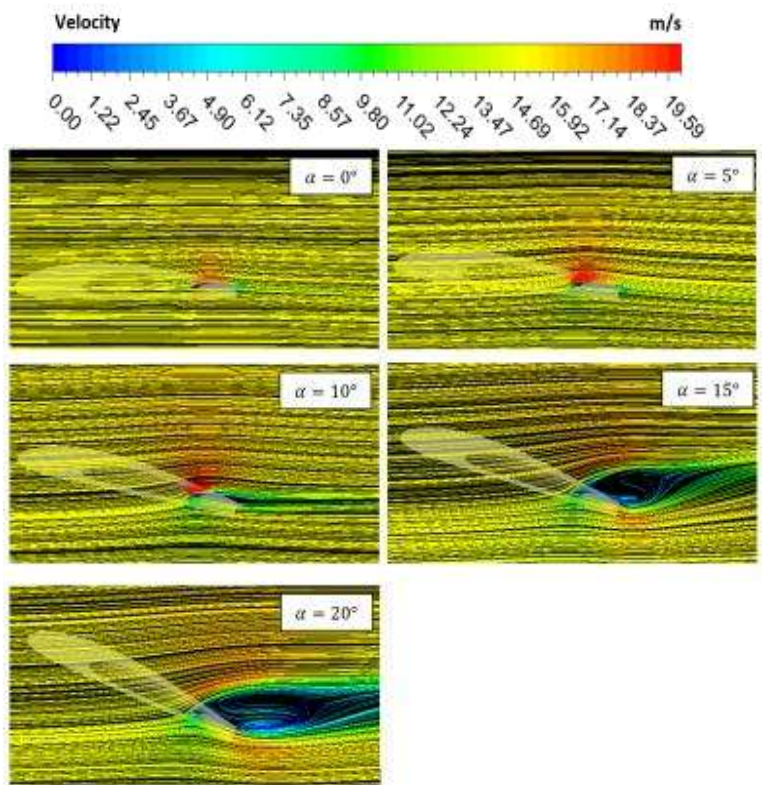

Gambar 13. Visualisasi Pola Streamline pada Sayap Internal

Karakteristik distribusi tekanan pada sayap internal $40 \%$ dan $50 \%$ terlihat sangat identik terutama bagian root sayap internal. Visualisasi pola streamline aliran kedua sayap dapat dilakukan pada salah satu sayap saja. Visualisasi pola streamline aliran yang ditunjukkan pada Gambar 13 diambil pada jarak $5 \mathrm{~mm}$ dari root sayap internal $40 \%$. Pola streamline menunjukkan bahwa aliran udara mengalir sempurna hingga trailing edge sayap pada sudut serang $0^{\circ}$ hingga $5^{\circ}$. Pada sudut serang $10^{\circ}$ mulai terjadi separasi aliran di daerah trailing edge dan terus berkembang hingga sudut serang $20^{\circ}$.

Pada sudut serang $15^{\circ}$ mulai terbentuk bubble separation pada sayap internal yang mengakibatkan tekanan pada permukaan sayap atas tidak terdristibusi merata. Hal ini dikarenakan aliran udara yang mengalir pada luasan permukaan sayap berkurang. Bubble separation terbesar terjadi pada sudut serang $20^{\circ}$, dimana bubble separation terbentuk dari leading edge hingga trailing edge sayap internal.

\section{Kesimpulan}

Dari hasil penelitian dapat diambil kesimpuan bahwa telescopic wing dengan konfigurasi flying wings dan glider mampu meningkatkan nilai $\mathrm{C}_{\mathrm{L}}$. Peningkatan nilai $\mathrm{C}_{\mathrm{L}}$ tertinggi untuk sayap internal $40 \%$ adalah sebesar $12,9 \%$ pada sudut serang $10^{\circ}$. Sedangkan pada sayap internal $50 \%$, peningkatan nilai $\mathrm{C}_{\mathrm{L}}$ tertinggi yaitu $14,9 \%$ pada sudut serang $10^{\circ}$. Peningkatan nilai $C_{D}$ terjadi seiring kenaikan sudut serang. Kenaikan nilai $\mathrm{C}_{\mathrm{D}}$ terbesar pada sayap internal $40 \%$ adalah sebesar $4,7 \%$ sedangkan pada sayap internal $50 \%$ kenaikan $C_{D}$ terbesar yaitu $9,5 \%$ pada sudut serang $20^{\circ}$. Distribusi tekanan sepanjang wingspan pada sayap internal tidak merata mulai dari sudut serang $15^{\circ}$ akibat dari wing tip vortices sayap eksternal. Wing tip voritces pada menyebabkan bubble separation pada leading edge yang terlihat dari pola streamline.

\section{Referensi}

[1] J. Vale, A. Leite, F. Lau, and A. Suleman, "Aero-structural optimization and performance evaluation of a morphing wing with variable span and camber," J. Intell. Mater. Syst. Struct., vol. 22, no. 10, pp. 1057-1073, 2011.

[2] J. Manzo and E. Garcia, "Demonstration of an insitu morphing hyperelliptical cambered span wing mechanism," Smart Mater. Struct., vol. 19, no. 2, 2010.

[3] J. Hall, K. Mohsenit, D. Lawrence, and P. Geuzaine, "Investigation of variable wing-sweep for applications in micro Air Vehicles," Collect. Tech. Pap. - InfoTech Aerosp. Adv. Contemp. Aerosp. Technol. Their Integr., vol. 4, no. September, pp. 2392-2402, 2005.

[4] J. Vale, F. Lau, A. Suleman, and P. Gamboa, "Multidisciplinary design optimization of a morphing wing for an experimental UAV," Collect. Tech. Pap. - 11th AIAA/ISSMO Multidiscip. Anal. Optim. Conf., vol. 4, no. May 2014, pp. 2639-2658, 2006. 
[5] J. Mestrinho, P. Gamboa, and P. Santos, "a Small UAV," no. April, pp. 1-18, 2011.

[6] M. Bashir, P. Rajendran, and A. Mule, "Investigation on ThreeDimensional CFD Validation for a Variable Span Morphing Wing," Asian J. Converg. ..., no. April, 2017.

[7] J. N. Ostler and W. J. Bowman, "Flight testing of small, electric powered unmanned aerial vehicles," Collect. Tech. Pap. - U.S. Air Force T E Days Transform. T E Enterp., vol. 2005, no. 3, pp. 484-495, 2005.

[8] P. Lauk and K. E. Unt, "Influence of miniflaps on sailplane flight characteristics," Aviation, vol. 19, no. 3, pp. 105-111, 2015.

[9] A. A. Alsahlan and T. Rahulan, "Aerofoil design for unmanned highaltitude Aft-swept flying wings," $J$. Aerosp. Technol. Manag., vol. 9, no. 3, pp. 335-345, 2017.

[10] B. Emmerson and D. Verstraete, "A post-stall experimental study of an eppler 387 airfoil at a reynolds number of 300,000," AIAA Scitech 2020 Forum, vol. 1 PartF, no. January, pp. 1-16, 2020. 